\title{
Intra Plate Stresses Using Finite Element Modelling
}

\author{
S. JAYALAKSHMI and S.T.G. RAGHUKANTH \\ Department of Civil Engineering, Indian Institute of Technology Madras, \\ Chennai, India; e-mail: sjayalakshmicivil@gmail.com
}

\begin{abstract}
One of the most challenging problems in the estimation of seismic hazard is the ability to quantify seismic activity. Empirical models based on the available earthquake catalogue are often used to obtain activity of source regions. The major limitation with this approach is the lack of sufficient data near a specified source. The non-availability of data poses difficulties in obtaining distribution of earthquakes with large return periods. Such events recur over geological time scales during which tectonic processes, including mantle convection, formation of faults and new plate boundaries, are likely to take place. The availability of geometries of plate boundaries, plate driving forces, lithospheric stress field and GPS measurements has provided numerous insights on the mechanics of tectonic plates. In this article, a 2D finite element model of Indo-Australian plate is developed with the focus of representing seismic activity in India. The effect of large scale geological features including sedimentary basins, fold belts and cratons on the stress field in India is explored in this study. In order to address long term behaviour, the orientation of stress field and tectonic faults of the present IndoAustralian plate are compared with a reconstructed stress field from the early Miocene (20 Ma).
\end{abstract}

Key words: seismic hazard, seismic activity, finite element model, palaeo-stress, optimisation.

Ownership: Institute of Geophysics, Polish Academy of Sciences;

(C) 2016 Jayalakshmi and Raghukanth. This is an open access article distributed under the Creative Commons Attribution-NonCommercial-NoDerivs license, http://creativecommons.org/licenses/by-nc-nd/3.0/. 


\section{INTRODUCTION}

The estimation of seismic hazard at a specified site imparts numerous challenges for an earthquake engineer. These challenges often arise from the existing limitations in the use of available earthquake catalogue. The first limitation is the lack of sufficient data at a specified site of interest. The activity of the surrounding seismic sources cannot be accurately determined from empirical models based on such sparse data. The second limitation is the estimation of hazard for earthquakes with large return periods exceeding 10,000 years. The earthquake catalogue cannot be considered as complete for this duration. Tectonic processes including plate movements, mantle convection and formation of faults significantly play an important role in seismic hazard. However, the procedures to overcome these limitations are directly and indirectly addressed by both engineers and geophysists. There have been several efforts to model tectonic plates in the past by various investigators (Bird and Piper 1980, Bird and Baumgardner 1984) making use of the available information on spatial locations of past earthquakes and GPS measurements. All these models are routinely used to evaluate long term seismicity and plate motion.

Among the various continental plates, the Indian plate experiences diffuse seismicity and the distribution of seismicity that varies from the active Himalayan boundary to the relatively stable regions of the continental shield. However, in the Indian context, Cloetingh and Wortel (1985) developed finite element model for Indo-Australian plate based on plate driving forces to study regional stress field in India. Although the predicted stress regimes from this model imparted awareness on the dynamics of Indian plate, not much instrumental data was available to validate these conclusions. Later on, finite element models developed by previous authors (Coblentz et al. 1995, Dyksterhuis et al. 2005) explored the various plate driving forces on the Indo-Australian plate and the effect of cratons, basins and fold belts on the stress field in continental Australia. Jayalakshmi and Raghukanth (2015) developed an engineering model for Indian plate to broadly explain seismic activity in India from the known plate driving forces, earthquake catalogue and GPS measurements. However, this model is based on the short term behaviour of the plate with prior information on the location of faults and the epicenters of past earthquakes. Recently, Müller et al. (2014) studied the evolution of stresses in various regions of Indian lithosphere based on palaeo-stress modelling by considering three geological time scales, namely Oligocene (33 million years ago), Miocene ( 20 million years ago) and present. Although the models explain the formation of various tectonic structures in Indian subcontinent from the simulated directions of maximum compressive stresses $\left(\sigma_{H \max }\right)$, these are not used for quantifying seismic ac- 
tivity. Such long term models are useful for engineers to estimate seismic hazard due to future earthquakes with small and large return periods. The availability of large sets of lithospheric stress data for the entire globe has improved understanding of mechanics of many continental tectonic plates (Zoback 1992). The latest stress maps are available from the World Stress Map, Release of 2008. The available data set on stress field in India can be used to develop a finite element model for Indian plate or Indo-Australian plate. Since the separation of Indian plate from the rigid Indo-Australian plate is a recently observed phenomenon reported by seismologists, modelling of Indo-Australian plate is likely to give better insights on evolution of long term stresses and faults (Royer and Gordon 1997, Conder and Forsyth 2001).

The focus of the present study is to develop a 2D finite element model of Indo-Australian plate for estimating seismic activity in India. The plate driving forces are applied on the ridges and subduction zones. The model parameters, including the material properties for all the geological provinces in India, are estimated by minimizing the error between the simulated and the observed stress field from the World Stress Map, Release 2008. Since the analysis is performed to simulate low order tectonic stresses, the models are assumed linear elastic. The potential regions for future earthquakes are identified and related with seismic activity in India. The potential risk due to earthquakes with small return periods (less than 5000 years) can be validated with the available Indian earthquake catalogue (NDMA 2010). However, no data is available for explaining seismic activity of events with large return periods (exceeding 5000 years). To overcome this difficulty, a reconstructed plate model from the early Miocene $(20 \mathrm{Ma})$ is analysed and the directions of the stress field are compared with the present day stresses and fault lines.

\section{MODEL SETUP}

The historic collision with Eurasia led to the formation of several geological and tectonic features in India. The Indian landmass consists of three geological regions, namely, the Himalayas, the Indo-Gangetic Plain and the Indian Shield which accommodate several geological provinces and tectonic faults. The geological provinces in India are shown in Fig. 1. A brief review of the various provinces is presented to broadly demarcate the important regional blocks in India. The southern boundary of the Himalayas contains sediments deposited by ancient Himalayan Rivers and the elevation of this range lies in between 0.25 to $0.8 \mathrm{~km}$. Further north, lies the Lesser Himalaya and this consists of mostly Palaeozoic sedimentary rocks. The average elevation in Lesser Himalaya is $2.5 \mathrm{~km}$. The Great Himalaya is the northernmost subprovince that comprises of crystalline metamorphic and igneous rocks. The average elevation in this region is about $5 \mathrm{~km}$. 


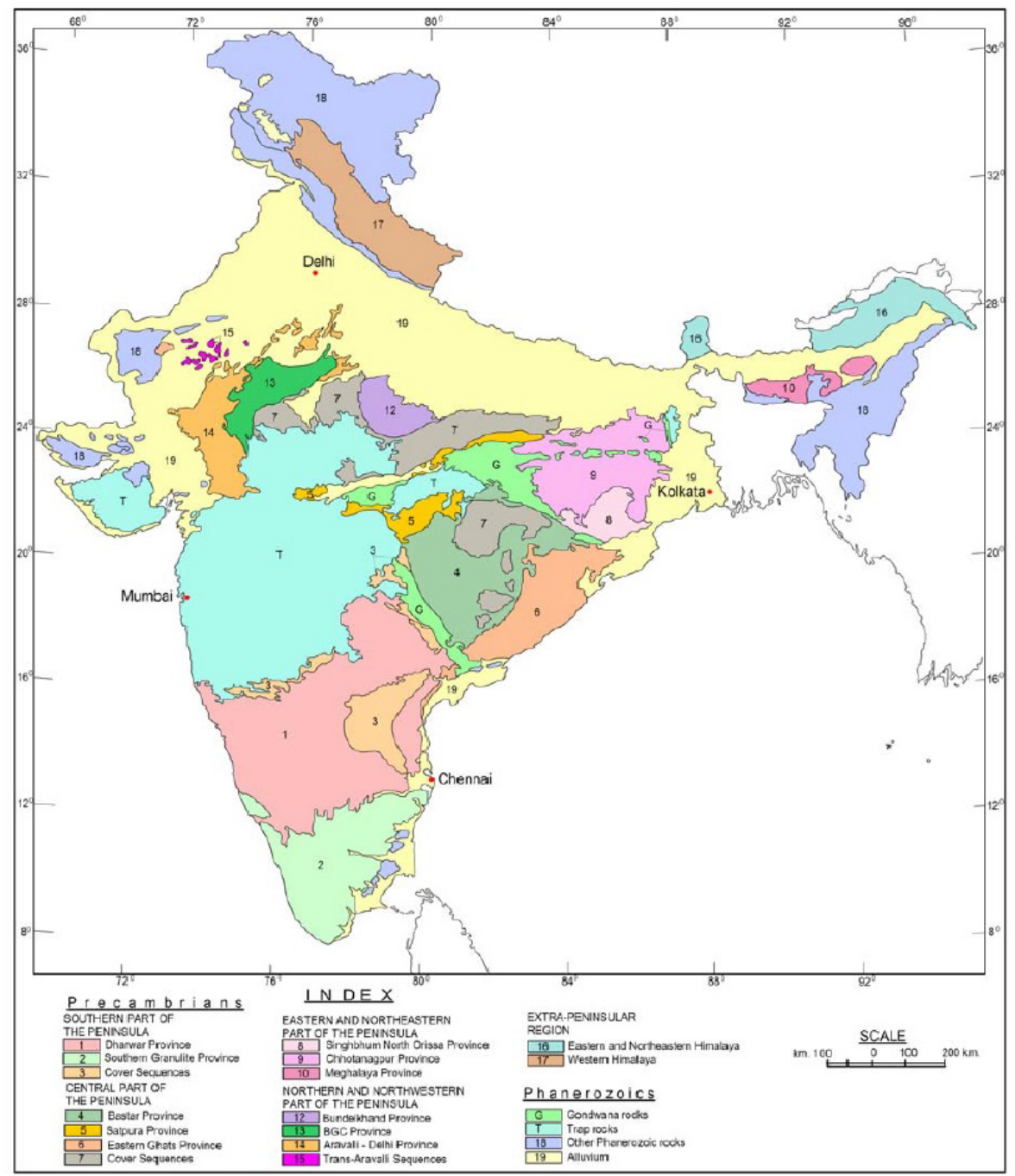

Fig. 1. Geological provinces in India (GSI 2000).

The Indo-Gangetic region comprises large massive alluvial plains. The region is a basin that lies south to the Himalaya and the sagging of the region is attributed to the collision of the Indian and the Eurasian plates. The basin embodies sediments flowing from the Himalayas and parts of the peninsular shield region. The thickness of the alluvial deposits in the Indo-Gangetic Plains is of the order of $1.5-6 \mathrm{~km}$ that covers the solid nature of its basement. The average elevation in this region is about $200 \mathrm{~m}$. 
The peninsular shield consists of a complex system of folds and faults in the basement rock, attributed to the intense tectonic activity during its evolution. This region contains majority of the rock formations and stratigraphic units in India. More than half of the shield is occupied by one of the oldest rocks of Archean era known as Dharwar.

In northeast India, the Archean rocks are formed in Shillong plateau and Mikir hills. Later during the Precambrian period, orogenic movements resulted in the formation of some isolated basins. Sedimentary rocks got deposited over the eroded surface of Archean rocks. Precambrian rocks in peninsular India occur in Cuddapah and Vindhyan basins. The Gondwana rocks which are younger than Precambrian rocks occur in three linear tracts along Son-Narmada-Damodar rivers alignment, along Mahanadi and Godavari rivers. The basaltic lava flows during the Mesozoic era resulted in the formation of Deccan traps. The area covered by these rocks is approximately about three hundred thousand square kilometers.

\subsection{Finite element model}

Finite element modelling of the Indo-Australian plate is carried out for the present day and the geologic past (early Miocene, $20 \mathrm{Ma}$ ) using ABAQUS 6.10.1. The Indian landmass is divided into 19 geological provinces based on the map shown in Fig. 1. These provinces are formed due to the historic collision of India with Eurasia and a brief review on the rock composition in these provinces is described in the previous section. The boundaries of the provinces are digitized from the map and incorporated in the Indian landmass of the Indo-Australian plate as shown in Fig. 2. The 2D finite element model of Indo-Australian plate is created using 42000 plane stress quadrilateral elements at a spatial resolution of $35 \mathrm{~km}$ between two nodes (Fig. 3), assuming a linear elastic model rheology which is valid for large scale models to simulate low order tectonic stresses.

The next step is to determine the plate driving forces acting on the plate. The topographic forces including ridge push and slab pull forces are to be applied in the model at the respective boundaries. The ridge push force (FRP) which arises due to elevated topography at mid-ocean ridges (MOR) is applied as a distributed pressure gradient normal to the strike of the midocean ridge (Wilson 1993).

This force can be quantitatively estimated from the expression in Eq. 1 given by Turcotte and Schubert (2002) as

$$
F_{R P}=\rho_{m} g \alpha_{v}\left(T_{m}-T_{0}\right)\left[1+\frac{2 \rho_{m} \alpha_{v}\left(T_{m}-T_{0}\right)}{\pi\left(\rho_{m}-\rho_{w}\right)}\right] k_{d} t,
$$




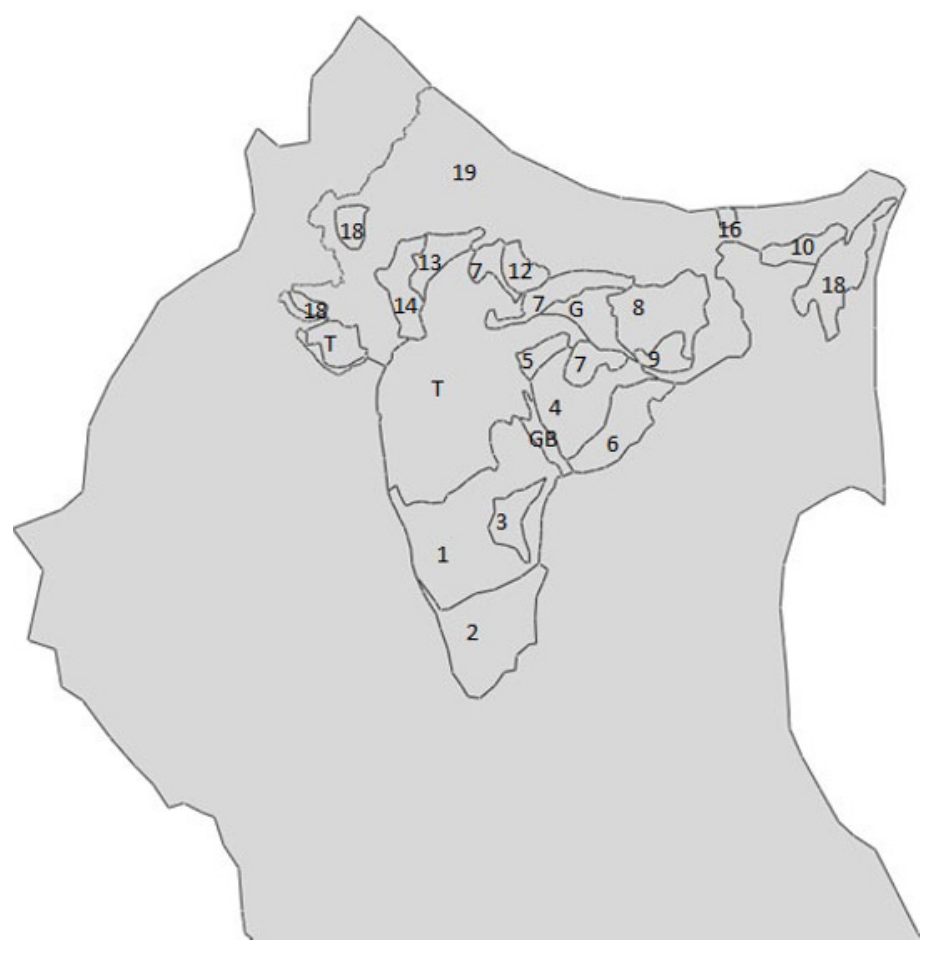

Fig. 2. Geological provinces modelled in India.

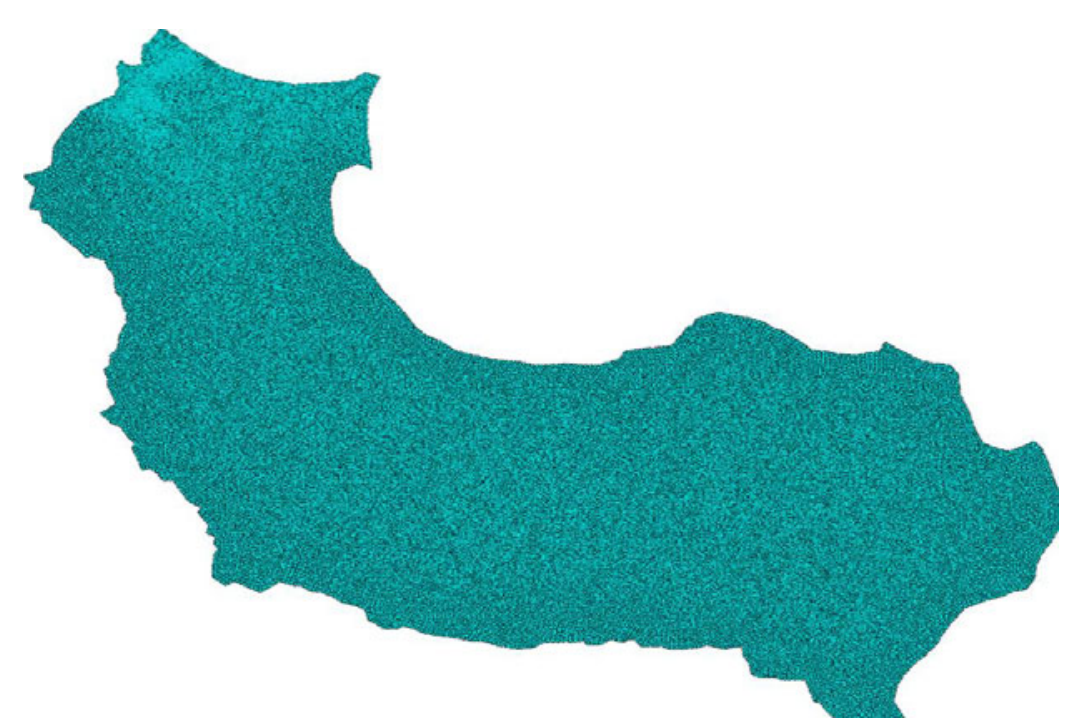

Fig. 3. Finite element mesh for the present day Indo-Australian plate. 
where $\rho_{m}$ is density of the mantle $\left(3300 \mathrm{~kg} / \mathrm{m}^{3}\right), g$ is the acceleration due to gravity $\left(10 \mathrm{~m} / \mathrm{s}^{2}\right), \alpha_{v}$ is the thermal expansion coefficient $\left(3 \times 10^{-5} / \mathrm{K}\right),\left(T_{m}-\right.$ $\left.T_{0}\right)$ is the temperature difference between mantle and surface $(1200 \mathrm{~K}), \rho_{w}$ is the density of water $\left(1000 \mathrm{~kg} / \mathrm{m}^{3}\right)$, thermal diffusivity $\left(k_{d}\right)$ can be taken as $1 \mathrm{~mm}^{2} / \mathrm{s}$, and $t$ is the age of lithosphere in seconds.

The slab pull forces originating in the subduction zones on the trench side due to the negative buoyancy of the down-going dense oceanic lithosphere is given by

$$
F_{S P}=2 \rho_{m} g \alpha_{v} b\left(T_{c}-T_{0}\right)\left(\frac{\kappa \lambda}{2 \pi u_{0}}\right)^{1 / 2}+2 \frac{\left(T_{c}-T_{0}\right) \gamma \Delta \rho_{o s}}{\rho_{m}}\left(\frac{\kappa \lambda}{2 \pi u_{0}}\right)^{1 / 2},
$$

where $b$ is the slab length, $\lambda$ is $4000 \mathrm{~km}, u_{0}$ is $50 \mathrm{~mm} / \mathrm{yr}, \gamma$ is $4 \mathrm{MPa} / \mathrm{K}, \Delta \rho_{o s}$ is $270 \mathrm{~kg} / \mathrm{m}^{3}$, and other parameters are described in Eq. 1. The ridge push and the slab pull forces acting at the various boundaries are computed according to the work of Dyksterhuis et al. (2005) and applied in the IndoAustralian plate model.

Due to the large uncertainties associated with the mantle drag forces, the estimation of these forces is a highly complex problem. This difficulty can be overcome by assuming a suitable boundary condition along the Himalayas in such a way that all the resistive forces to the driving plate are accommodated in this boundary to maintain mechanical equilibrium of the plate. Therefore, in this study the northern most boundary of the plate along the Himalaya is assumed to be fixed.

\subsection{Material properties}

The Indo-Australian continental plate is composed of numerous geological structures with varying material properties. It will be interesting to study the effect of these structures on the stress field in the plate. However, the estimation of both material properties (Young's modulus, $E$, and Poisson's ratio, v) and forces for the Indian plate from known stress directions is a highly complex problem. Since the effects on stress field can be better understood with and without the presence of these geological structures, the plate driving forces are applied on the boundaries of two models: first, a homogenous model with uniform material properties for the entire plate; second, a heterogeneous model with varying material properties at specific regions in the plate. The directions of maximum horizontal compressive stress $\left(\sigma_{H \max }\right)$ are obtained and compared with the observed stress orientations (Fig. 4) reported in the world stress map project (Zoback 1992). A residual misfit is calculated between the simulated and the measured stress orientations over each geological province. Thus, the objective function is defined as the sum of squares of all the misfits over the identified provinces given by 


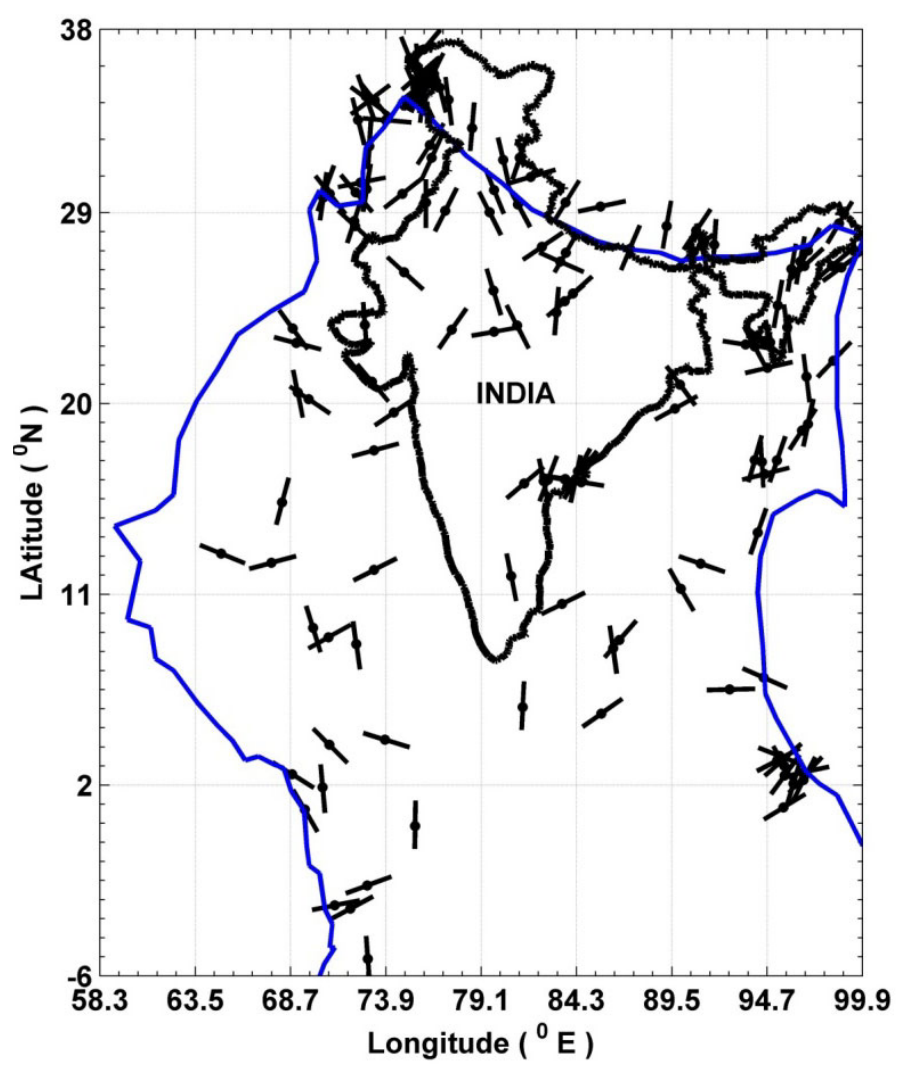

Fig. 4. Directions of the most compressive horizontal stress in Indo-Australian plate (World Stress Map Project).

$$
\varepsilon^{2}=\sum_{k=1}^{8}\left[\left(\theta_{H, k}^{r}-\theta_{H, k}^{s}\right)^{2}\right],
$$

where $\theta_{H}$ is the direction of maximum horizontal compressive stress from the measured $(r)$ and simulated $(s)$ averaged over each of the $k$-th province. The minimization of the objective function is carried out by implementing the Genetic Algorithm optimization tool (GA) in Matlab. A program code is developed in Matlab that combines the ABAQUS python script for the model with the GA optimization tool. The forces implemented in the IndoAustralian plate model are listed in Table 1 and illustrated in Fig. 5.

The misfits for important provinces in the homogenous model are listed in Table 2. Apart from the plate driving forces, the behaviour of the plate is largely governed by the elastic material properties, $E$ and $v$, of the various geological provinces. The relative stiffness of these regions is dependent on 
Table 1

Forces applied to the contemporary and Miocene models (Dyksterhuis et al. 2005)

\begin{tabular}{|l|c|c|}
\hline \multicolumn{1}{|c|}{ Location } & Contemporary & Miocene \\
\hline Mid Oceanic Ridge & 1.90 & 1.10 \\
Australia-Antartica Discordance & 2.10 & 1.70 \\
Papua New Guinea & 3.80 & - \\
Banda Arc & -0.50 & - \\
Java & -0.30 & -0.30 \\
New Hebrides & 1.00 & - \\
Solomon & 1.20 & - \\
Sumatra & 2.00 & 2.00 \\
New Zealand & 2.40 & 2.40 \\
Southern New Zealand Alps & 2.80 & 2.80 \\
Carol & - & -0.60 \\
Ontong Plateau & - & 2.50 \\
\hline
\end{tabular}

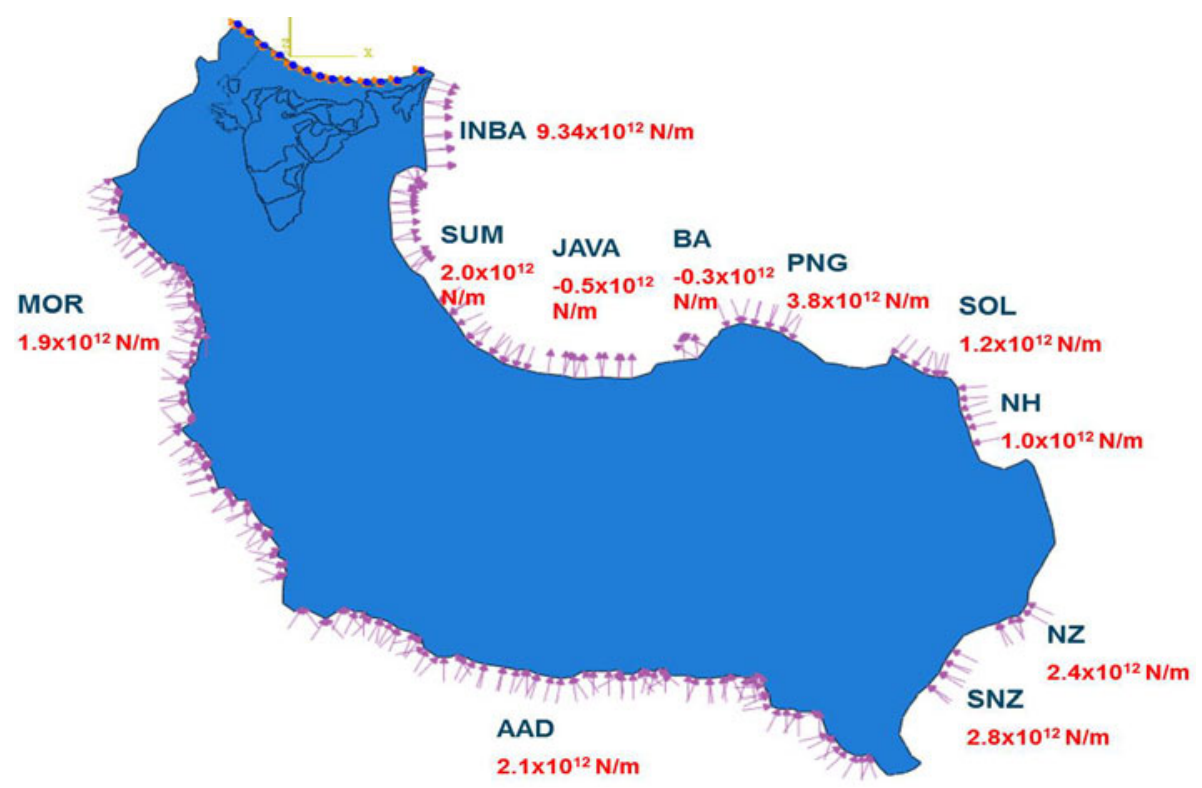

Fig. 5. Plate driving forces acting on present day Indo-Australian plate.

the material properties and expressed in terms of flexural rigidities. The homogenous model discussed in the previous section cannot distinguish regions of different rigidities and hence it is required to vary the material property within each province for simulating a more realistic behaviour. 
Table 2

Residual misfit between simulated and measured stress orientations

\begin{tabular}{|l|c|c|}
\hline \multicolumn{1}{|c|}{ Province } & $\begin{array}{c}\text { Misfit } \varepsilon^{2} \\
\text { Homogenous Model }\end{array}$ & Heterogeneous Model \\
\hline Dharwar & 1.50 & 0.91 \\
Southern Granulite & 0.32 & 0.12 \\
Godavari Graben & 2.33 & 0.45 \\
Gujarat region & 0.14 & 0.14 \\
Indo-Gangetic Basin & 0.69 & 0.64 \\
Meghalaya & 0.09 & 0.01 \\
Son-Narmada Rift & 1.40 & 1.06 \\
Bundelkhand & 0.04 & 0.10 \\
Total Misfit & 6.51 & 3.43 \\
\hline
\end{tabular}

Since the flexural rigidity of the plate depends on Young's modulus, thickness and Poisson's ratio, the error defined in Eq. 3 becomes a non-linear function of all these parameters. Due to the complexities involved in estimating the bounds for all the parameters, only the Young's modulus of each geological province is varied in the present study.

Therefore, keeping the thickness and Poisson's ratio constant, the Young's modulus of rock is constrained for the various geological provinces. Several studies have postulated that Young's modulus ranges between $10^{10}$ and $10^{12} \mathrm{~Pa}$ (Turcotte and Schubert 2002, Pauselli and Federico 2003). The thickness used in the various provinces is indicated in Table 3. The relative strengths of the individual provinces are estimated by altering the Young's moduli $(E)$ of the materials in the various geological provinces in the specified range. The effect of varying material properties in the Indian subcontinent is better understood by comparing the results of the model with homogenous material properties. The Young's modulus of each province is determined by minimizing the objective function in Eq. 3 through extensive exploration of unknown parameter space using Genetic Algorithm (GA) optimization. The residual misfits obtained for important provinces are shown in Table 2. It is observed that the heterogeneous model with varying material properties lowers the total residual misfit by almost half. The Young's modulus of each province obtained from optimization is indicated in Table 3. After obtaining the material properties, it will be of interest to compute rigidities of various provinces from their respective Young's moduli.

Table 3 lists the value of rigidities determined from the heterogeneous model of Indo-Australian plate. The observed rigidities for most of the provinces are in good comparison with the overall flexural rigidity of Indian plate as inferred from gravity anomalies, which is reported as $5 \times 10^{24} \mathrm{Nm}$ for the 
Indian plate (Lyon-Caen and Molnar 1985, Caporali 1997). However, for the provinces including sedimentary basins of Bundelkhand, alluvium, Deccan traps, Godavari Graben and Meghalaya, the observed rigidities are quite high which can be attributed to the large thickness used in the model.

Table 3

Provinces and the material properties from optimization

\begin{tabular}{|l|c|c|c|}
\hline \multicolumn{1}{|c|}{ Province } & Thickness $[\mathrm{km}]$ & $\mathrm{E} \times 10^{10}[\mathrm{~Pa}]$ & Rigidity $[\mathrm{Nm}]$ \\
\hline Crust & 60 & 9.35 & $1.85 \mathrm{E}+24$ \\
Dharwar (1) & 150 & 1.28 & $3.95 \mathrm{E}+24$ \\
SouthernGranulite (2) & 150 & 2.63 & $8.11 \mathrm{E}+24$ \\
CoverSequences (3, 7) & 200 & 5.35 & $3.92 \mathrm{E}+25$ \\
Bastar Craton (4) & 200 & 0.22 & $1.60 \mathrm{E}+24$ \\
Satpura (5) & 130 & 0.87 & $1.76 \mathrm{E}+24$ \\
Eastern Ghats (6) & 130 & 2.48 & $4.98 \mathrm{E}+24$ \\
Singhbhum (8) & 150 & 9.35 & $7.70 \mathrm{E}+24$ \\
Chhotanagpur (9) & 150 & 1.77 & $5.48 \mathrm{E}+24$ \\
Meghalaya (10) & 300 & 4.52 & $1.12 \mathrm{E}+26$ \\
Bundelkhand (12) & 300 & 1.79 & $4.43 \mathrm{E}+25$ \\
BGC (13) & 150 & 9.30 & $2.87 \mathrm{E}+25$ \\
Aravalli-Delhi (14) & 150 & 4.02 & $1.24 \mathrm{E}+25$ \\
Gondwana Rocks (G) & 150 & 3.46 & $1.56 \mathrm{E}+25$ \\
Trap Rocks (T) & 150 & 5.52 & $2.12 \mathrm{E}+25$ \\
Alluvium (19) & 150 & 6.72 & $7.13 \mathrm{E}+25$ \\
\hline
\end{tabular}

\section{COMPARISON WITH STRESS DATA}

The results of the numerical approach show that the directions of the maximum horizontal compressive stress, $\sigma_{H \max }$, can be modeled by placing regions of varying material properties. The Indian lithosphere is modelled by placing regions of varying material properties and large differences in the direction of $\sigma_{H \max }$ are observed around these regions. As a consequence of placing regions of varying rigidities, more perturbations are observed in the spatial rotations of $\sigma_{H \max }$. Materials with higher rigidity deform less under a given loading, compared to weaker regions. This results in deviation of stress directions within strong regions around weaker regions. The comparison with observed stress directions in the Indian lithosphere is shown for both homogenous and heterogeneous models in Figs. 6 and 7.

It is observed that the directions of $\sigma_{H \max }$ predicted by a model with heterogeneous material properties exhibit more perturbations compared to those simulated by the homogeneous model. The observed directions $\sigma_{H \max }$ are 


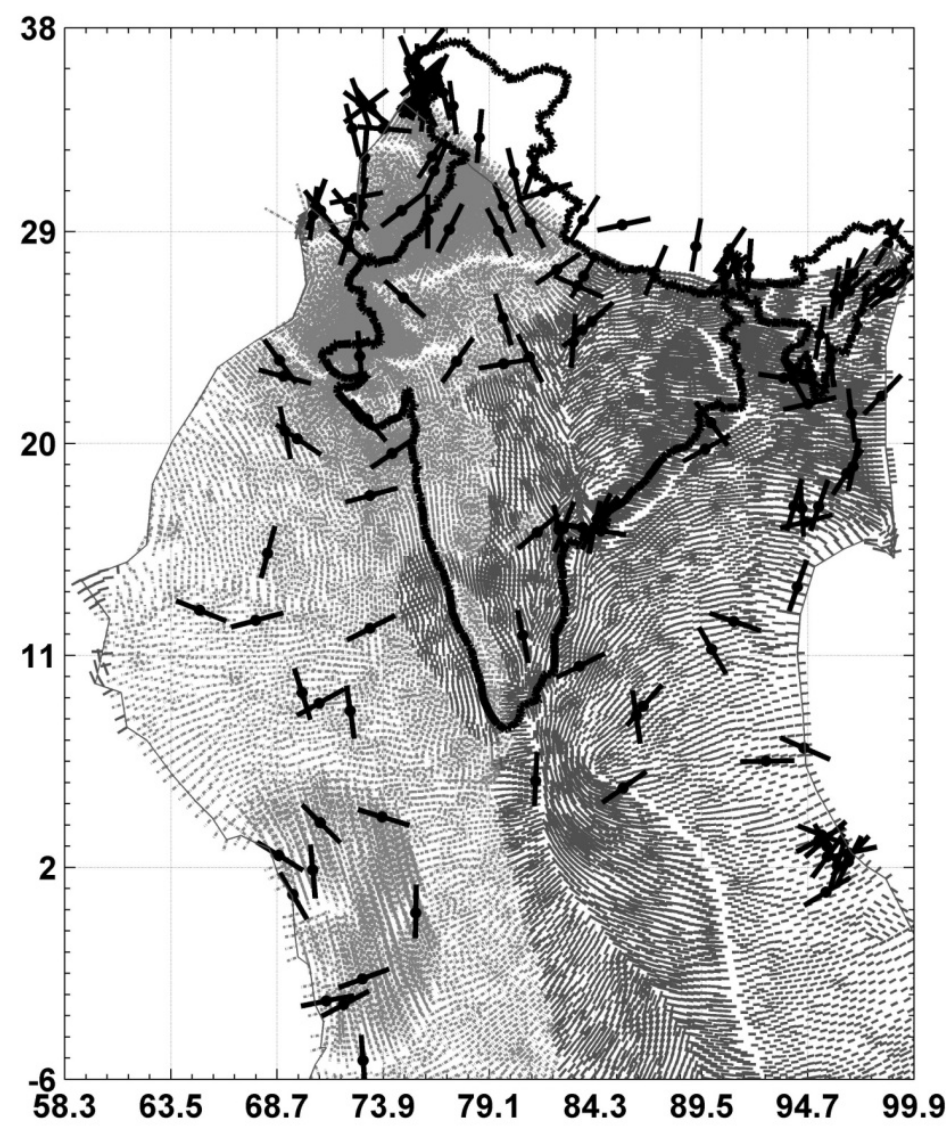

Fig. 6. Directions of maximum horizontal compressive stress $\left(\sigma_{H \max }\right)$ in India as simulated from the homogeneous model. Dark solid lines indicate compressive stress and grey dotted lines indicate tensile stresses. Black thicker lines are the measured stress orientations in India.

highlighted in few regions of India, including Himalayas, Godavari basin and western margins of Bastar province (Fig. 8).

The stress directions in the regions of Deccan trap rocks, Godavari Basin (GB) and Bastar province rotate by approximately $90^{\circ}$ over an area of $35000 \mathrm{~km}^{2}$. The directions observed in the homogenous model are rotated by almost $60^{\circ}$ in the heterogeneous model between the Bastar and the Singhbhum province. The provinces can be identified from Figs. 1 and 3. The simulated rotations follow the observed rotations in $\sigma_{H \max }$ orientation in most of the provinces with reasonably low residual misfits compared to homogenous models. Few spatially rapid variations in $\sigma_{H \max }$ directions are 


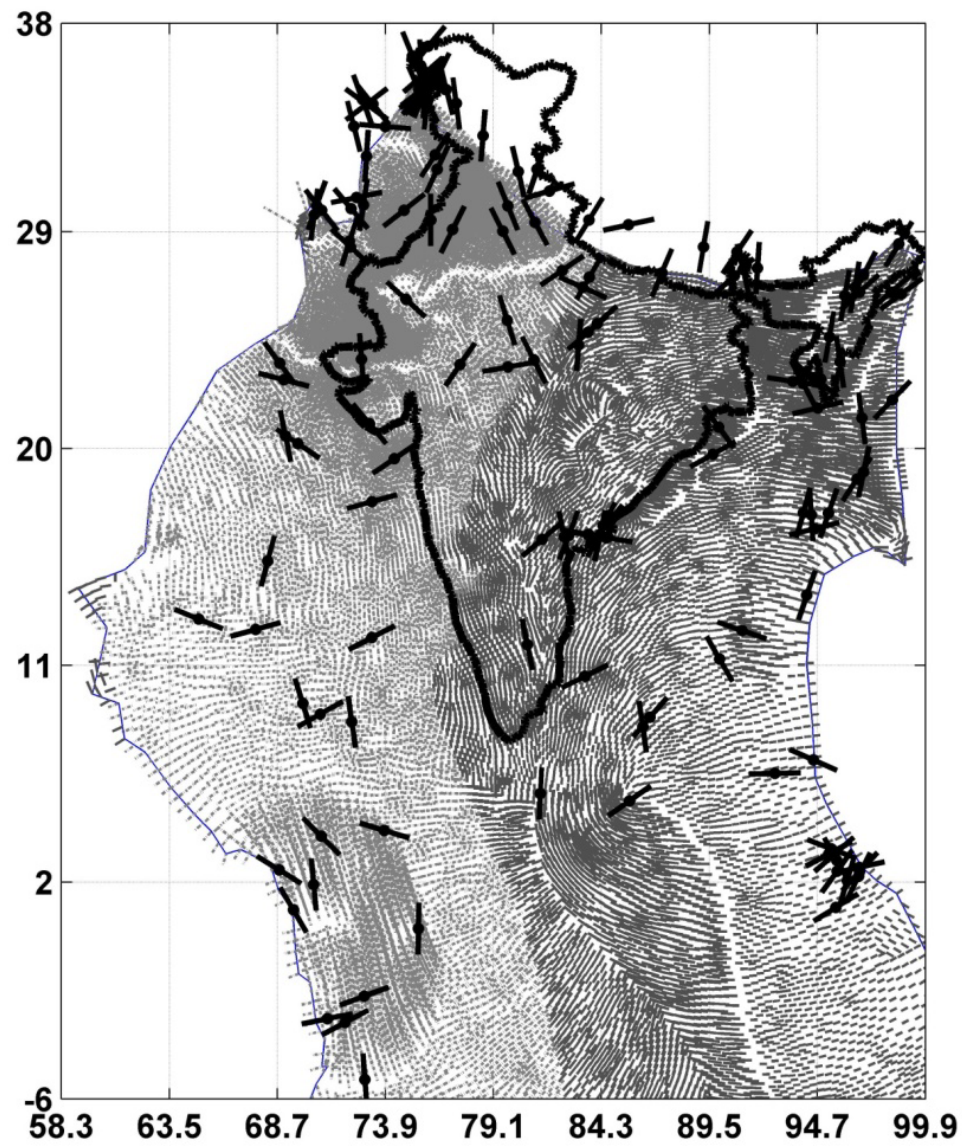

Fig. 7. Directions of maximum horizontal compressive stress $\left(\sigma_{H \max }\right)$ in India as simulated from the heterogeneous model. Dark solid lines indicate compressive stress and grey dotted lines indicate tensile stresses. Black thicker lines are the measured stress orientations in India.

observed in the homogeneous model because of the large thickness assumed for the cratonic provinces. These are significant in the eastern margins of Dharwar craton (Fig. 8a). However, the stress directions in regions of Bundelkhand and Meghalaya are not much affected by material heterogeneities which can be attributed to relatively large thickness in these regions. The residual misfit is comparatively low for almost all the provinces for the heterogeneous model (Table 2). Now, it will be of interest to compare the magnitudes of stress in India as obtained from both homogenous and heterogeneous models. Contours of Von Mises stress are obtained for the models and shown along with the fault map of India (GSI 2000) in Figs. 9 and 10. 
(a)

(b)
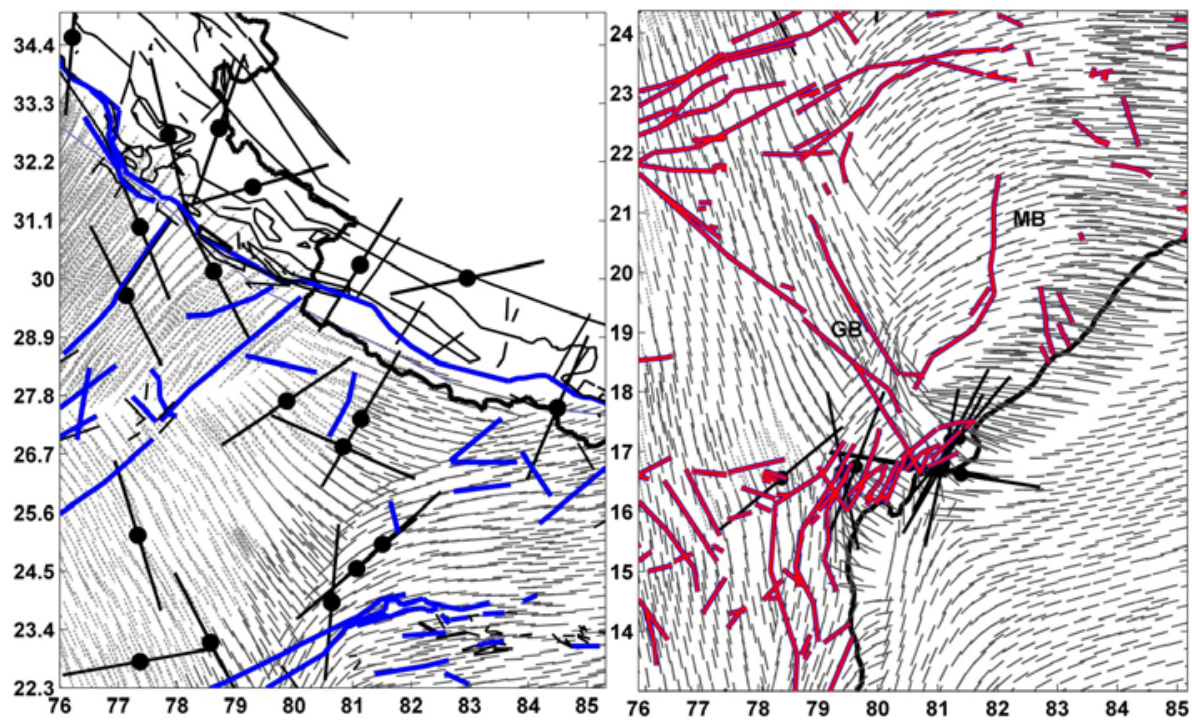

Fig. 8. Directions of maximum horizontal compressive stress $\left(\sigma_{H \max }\right)$ simulated from the heterogeneous model. Long thick lines represent the fault lines passing through the region: (a) Himalaya, (b) Godavari and Mahanadi Basin (GB, MB).

It is observed that significant variation in the magnitude of stresses is obtained in different provinces of Indian lithosphere in presence of material inhomogeneity. While the homogenous model predicts relatively large stresses in northern part of Dharwar province, Gujarat region, Son-narmada rift zone, and Singhbhum province, the heterogeneous model lowers the stresses in these regions by almost an order of magnitude. The stress contours presented for homogenous model in Fig. 9 and heterogeneous model in Fig. 10 can be compared with the seismic activity in India. The plate boundary zones with highest seismic activity are represented by maximum stresses by both the models. These boundary zones include Himalaya in the north, Indo-Burmese and Andaman Arc in the east and Mid-Oceanic ridge in the southwest. However, seismicity in other regions within India is also visible from the stresses. In the homogenous model (Fig. 9), high stresses are also observed in few intra plate regions including trap rocks $(\mathrm{T})$, Gondwana rocks $(\mathrm{G})$ and Chhotanagpur province (9). The increase in stress compared to other regions is attributed to the relative low thickness used in the homogenous model. In heterogeneous model (Fig. 10), the modelled stresses are different from those obtained for homogenous model. In this case, stress concentrations are observed in Godavari Graben, BGC and Aravalli-Delhi provinces $(13,14)$ and southern margin of Singhbhum province (8). These are regions of high 


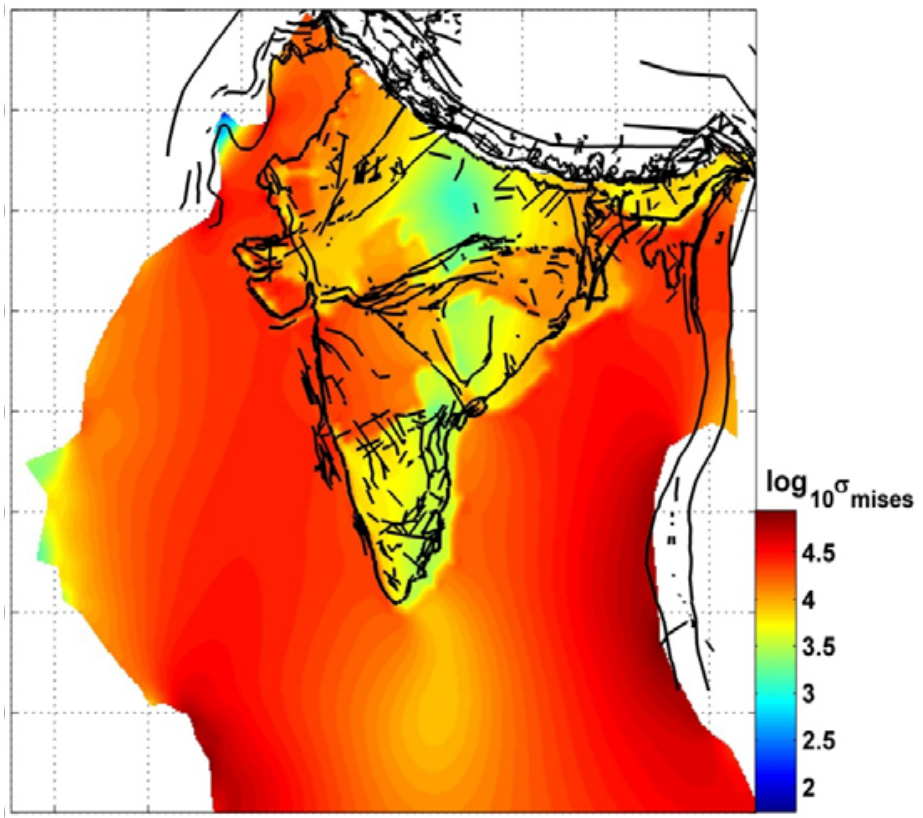

Fig. 9. Von Mises stress (in MPa) contours for homogeneous model with constant $E$.

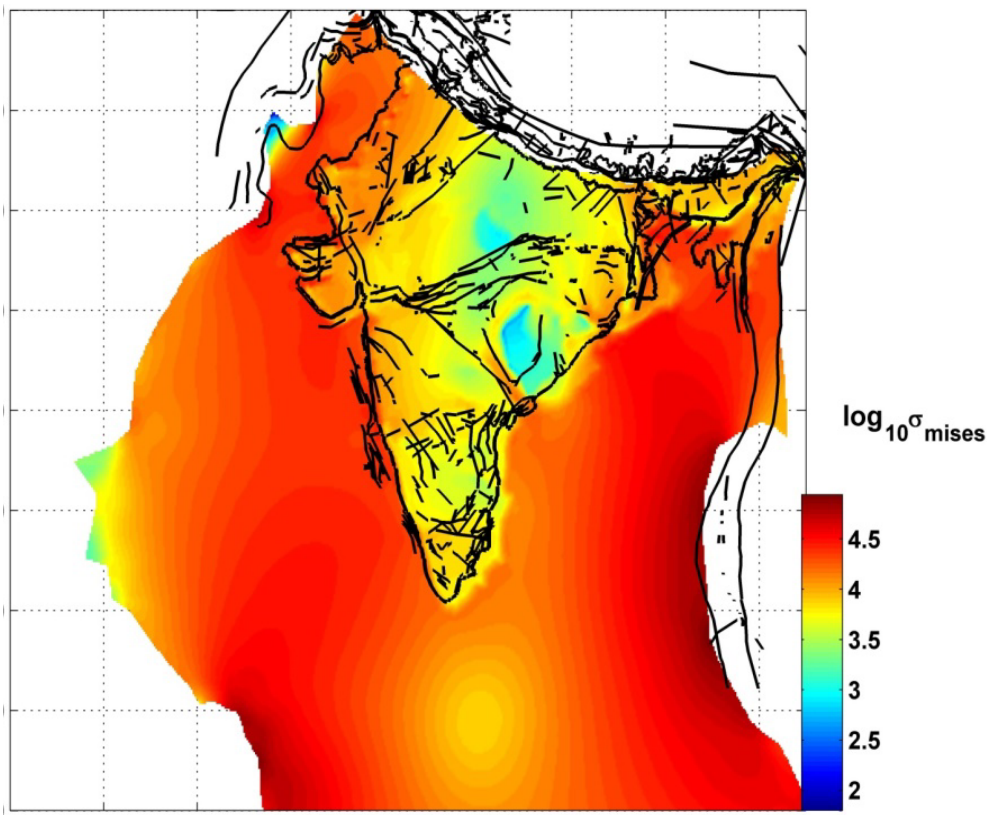

Fig. 10. Von Mises stress (in MPa) contours for the heterogeneous model with varying $E$. 
seismic activity in the intra plate regions. The northwestern margin of India with sedimentary deposits of alluvium (province 19) is demarcated by high stresses and the region is prone to potential seismic activity in future. It is also observed that the boundaries of the provinces are distinguished clearly from the modelled stresses.

\section{PALAEO STRESS FIELD IN INDIA}

The seismic activity in India is represented using the modelled present day stresses by comparing the stress fields from homogenous and heterogeneous models. The simplest approach to validate the stress contours is to compare it with the latest available Indian earthquake catalogue (NDMA 2010), and obtain quantities including stresses, strain rates and fault slip rates. However, all these comparisons hold good for estimating seismicity due to earthquakes of return periods within the span of the catalogue (less than 5000 years). This approach holds a major limitation while addressing seismicity due to earthquakes with large return periods, exceeding the span of the catalogue. Present-day stress modelling might not help to explain such earthquakes because long term behaviour of the plate plays a major role in such situations. The study of long term behavior involves the use of reconstructed plate models from geological past and comparison stress fields with the present day tectonic structures. Therefore, in the present study a palaeo-stress model for the early Miocene $(20 \mathrm{Ma})$ is also developed using reconstructed plate boundary configurations (Hall 2002, Dyksterhuis et al. 2005). The magnitudes of the forces computed by Dyksterhuis et al. (2005) based on age-area distribution of ocean crust around Australia are used to obtain estimates of spatial distribution and magnitude of ridge push and slab pull forces. Material properties are kept constant for the plate due to the lack of understanding of the evolution of various provinces during the geologic past. The forces applied in the palaeo-stress model are shown in Fig. 11.

The model subjected to these loads is analyzed assuming fixed boundary condition along the northernmost plate boundary and the stress patterns are studied for the Indian subcontinent. The direction of stress in this region is different when compared to that of the present day stresses (Fig. 12). However, in the Indian lithosphere, it is important to associate these stress directions with the reactivation histories of many tectonic features. In early Miocene, the Indian land mass laid further south and the collision with Eurasia had not begun. The partial coupling with Burma plate had initiated during this period which resulted in the northward movement of Burma on the present day Sagaing fault line (Hall 2002).

Tensile stresses are most predominant on the western part of the Indian subcontinent, while eastern half is dominated by compression. The present day model indicates $\sigma_{H \max }$ orientations in the northeast towards the trench, 


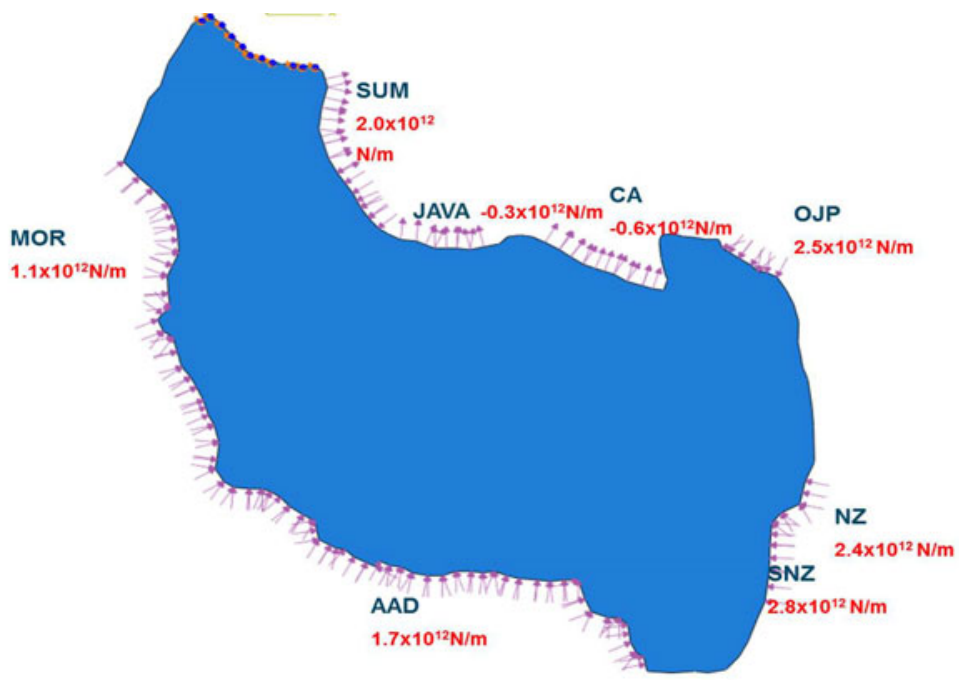

Fig. 11. Plate driving forces acting on the reconstructed Indo-Australian plate from the early Miocene (Dyksterhuis et al. 2005).

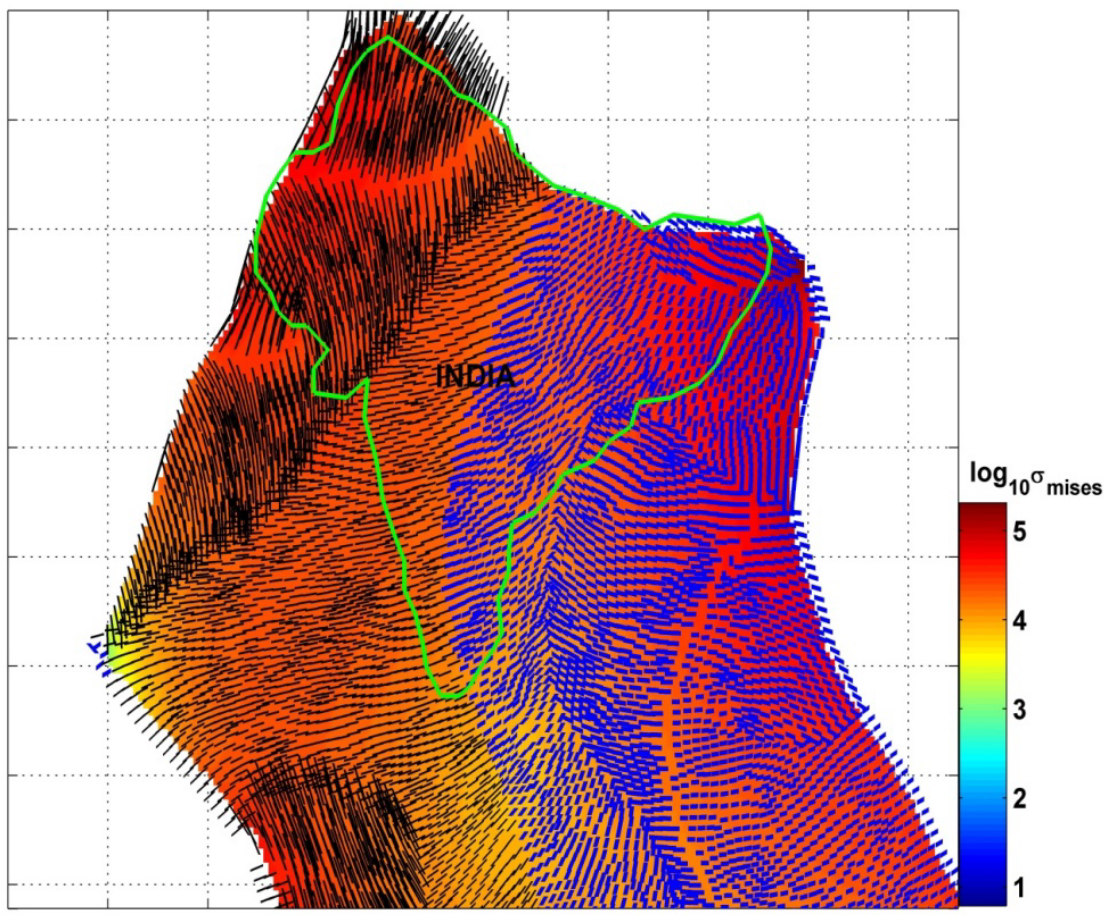

Fig. 12. Von Mises stress (in $\mathrm{MPa}$ ) contour with the directions of $\sigma_{H \max }$ on the palaeo stress model. 


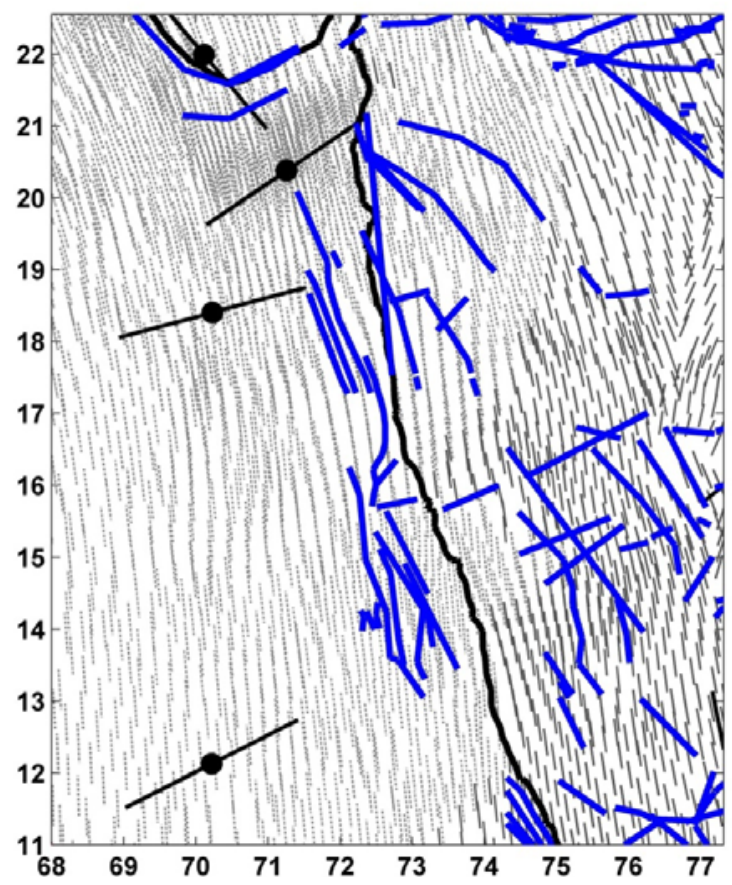

Fig. 13. The directions of present day $\sigma_{H \max }$ on the western margin of Peninsular India. The dark thick lines indicate the tectonic faults.

while the direction is northward along the Indo-Burmese border in the Miocene model. There are large differences in orientations of $\sigma_{H \max }$ over the western and eastern coastlines of Peninsular India in the palaeo-model compared to those of the present. The modelled $\sigma_{H \max }$ orientations correlate well with the fault reactivation histories of these regions. For example, the directions of $\sigma_{H \max }$ in the western coastal margin of Peninsular India are shown in Fig. 13. A deviation from a NW-SE orientation in the early Miocene to a general NE-SW at present is observed. This observation is consistent with the existence of many faults that lie parallel to the coast line (Fig. 13). The simulated $\sigma_{H \max }$ directions lie oblique to the coastline during the early Miocene indicated in Fig. 12 and normal to the coastline at present as shown in Fig. 13. In the Himalayas, Joshi and Hayashi (2010) studied the present day tectonic stress field and deformation numerically, to infer the numerous contradictory faulting patterns. The simulated $\sigma_{H \max }$ directions in the present day model are consistent with the observed orientations in the Himalayas (Fig. 8a). The palaeo-stress model indicates evidence for tensile stress regime and normal faulting during early Miocene. These are indicated by the reactivation histories of numerous EW striking tensile faults in these regions. 


\section{SUMMARY AND CONCLUSIONS}

Finite element model of Indo-Australian plate is developed in this article to represent seismic activity in India. The geological provinces in India are included in the model by varying the Young's modulus and thickness of these regions. The Young's moduli of the geological provinces are obtained by minimizing the error between the directions of the simulated stress field and observed stress field from the World Stress Map, Release 2008. The material flexural rigidities are estimated for all the geological provinces in India and these values are in good comparison with the reported flexural rigidity from gravity anomaly studies (Caporali 1997). The simulated $\sigma_{H \max }$ orientations show larger perturbations for the model with heterogeneous material properties compared to homogenous model. The directions of the simulated stress field are in good agreement with the observed stress field. The magnitude of stresses obtained from the model with all the geological provinces demarcates all the potential regions of future seismicity. The representation of seismic activity can be validated with the available earthquake catalogue for India. However, for earthquakes with large return periods (exceeding the span of the catalogue, 5000 years), difficulties arise due to lack of sufficient data. Therefore, in the present study, a reconstructed model from the early Miocene (20 Ma) is analyzed and the directions of stress fields are compared with present day stresses and fault lines. The $\sigma_{H \max }$ directions in the Miocene model and the fault line orientations in many of the regions in India provide sufficient evidences to support that the seismic activity in India can be represented by the simulated stresses.

While the problem of seismic hazard estimation follows a way ahead, the present study is limited to the representation of seismic activity in India. The stress contours presented in this work provide guidelines to quantify activity of an individual earthquake source or a fault. At any region of engineering interest, the activity of each fault can be distributed based on the magnitude of stresses. Since the stresses are also consistent with the reconstructed plate model, the model overcomes the difficulty of non-availability of data with respect to earthquakes of large return periods. In this way, the finite element model provides a better path towards the problem of seismic hazard by quantifying seismic activity. As mentioned, for the estimation of seismic hazard, one has to also quantify the peak ground response (acceleration/velocity/ displacement) at an individual site. Unlike crustal strains and stresses, the surface ground motions at any desired site depend on the local features such as topography, material properties of the medium and soil effects. The study of ground motions combined with earthquake source characterization gives a complete estimate of seismic hazard at any given site. These aspects shall be addressed in a future work. 


\section{References}

Bird, P., and J. Baumgardner (1984), Fault friction, regional stress, and crust-mantle coupling in southern California from finite element models, J. Geophys. Res. 89, B3, 1932-1944, 2156-2202, DOI: 10.1029/JB089iB03p01932.

Bird, P., and K. Piper (1980), Plane-stress finite-element models of tectonic flow in southern California, Phys. Earth Planet. In. 21, 2-3, 158-175, DOI: 10.1016/0031-9201(80)90067-9.

Caporali, A. (1997), Rheology of the Indian and Tarim plates in the karakoram continent-to-continent collision zone, Ann. Geophys. 40, 5, 1057-1067, DOI: 10.4401/ag-3840.

Cloetingh, S., and R. Wortel (1985), Regional stress field of the Indian plate, Geophys. Res. Lett., 12, 2, 77-80, DOI: 10.1029/GL012i002p00077.

Coblentz, D.D., M. Sandiford, R.M. Richardson, S. Zhou, and R. Hillis (1995), The origins of the intraplate stress field in continental Australia, Earth Planet. Sci. Lett. 133, 3-4, 299-309, DOI: 10.1016/0012-821X(95)00084-P.

Conder, J.A., and D. Forsyth (2001), Seafloor spreading on the south Indian ridge over the last one million years: a test of the capricon plate hypothesis, Earth Planet. Sci. Lett. 188, 1-2, 91-105, DOI: 10.1016/S0012-821X(01)00326-0.

Dyksterhuis, S., R. Albert, and R. Müller (2005), Finite-element modelling of contemporary and palaeo-intraplate stress using abaqus, Comput. Geosci. 31, 3, 297-307, DOI: 10.1016/j.cageo.2004.10.011.

GSI (2000), Seismotectonic atlas of India and its environs, Technical Report, Geological Survey of India.

Hall, R. (2002), Cenozoic geological and plate tectonic evolution of SE Asia and the sw Pacific: computer-based reconstructions, model and animations, J. Asian Earth Sci. 20, 4, 353-431, DOI: 10.1016/S1367-9120(01)00069-4.

Jayalakshmi, S., and S.T.G. Raghukanth (2015), An engineering model for seismicity of India, Geomatics Nat. Hazards Risk 6, 1, 1-20, DOI: 10.1080/ 19475705.2013.815282.

Joshi, G., and D. Hayashi (2010), Development of extensional stresses in the compressional setting of the himalayan thrust wedge: inference from numerical modelling, Nat. Sci. 2, 7, 667-680, DOI: 10.4236/ns.2010.27083.

Lyon-Caen, H., and P. Molnar (1985), Gravity anomalies, flexure of the Indian plate, and the structure, support and evolution of the Himalaya and Ganga Basin, Tectonics 4, 6, 513-538, DOI: 10.1029/TC004i006p00513.

Müller, R., V. Yatheesh, and M. Shuhail (2014), The tectonic stress field of India since the Oligocene, Gondwana Res. 28, 2, 612-624, DOI: 10.1016/j.gr. 2014.05.008.

NDMA (2010), Development of probabilistic seismic hazard map of India, Technical Report, National Disaster Management Authority, Government of India. 
Pauselli, C., and C. Federico (2003), Elastic modeling of the Alto Tiberina normal fault (central Italy): geometry and lithological stratification influences on the local stress field, Tectonophysics 374, 1-2, 99-113, DOI: 10.1016/ S0040-1951(03)00235-X.

Royer, J.Y., and R.G. Gordon (1997), The motion and boundary between the Capricon and Australian plates, Science 277, 5330, 1268-1274, DOI: 10.1126/ science.277.5330.1268.

Turcotte, D.L., and G. Schubert (2002), Geodynamics, 2nd ed., Cambridge University Press, Cambridge.

Wilson, M. (1993), Plate-moving mechanisms: constraints and controversies, J. Geol. Soc. 150, 5, 923-926, DOI: 10.1144/gsjgs.150.5.0923.

Zoback, M.L. (1992), First- and second-order patterns of stress in the lithosphere: The world stress map project, J. Geophys. Res. Solid Earth 97, B8, 1170311728, DOI: $10.1029 / 92 J B 00132$.

Received 26 February 2015 Received in revised form 25 November 2015 Accepted 8 December 2015 